Elsevier required licence: (c) $<2017>$. This manuscript version is made available under the CC-BY-NC-ND 4.0 license http://creativecommons.org/licenses/bync-nd/4.0/ 


\title{
"Robbing behavior" and re-immobilization of nanoscale zero-valent iron (nZVI) onto electrospun polymeric nanofiber mats for trichloroethylene (TCE) remediation
}

\author{
Jiawei Ren, Leonard D. Tijing * Ho Kyong Shon * \\ Centre for Technology in Water and Wastewater, School of Civil and Environmental Engineering, University of \\ Technology Sydney, P. O. Box 123, 15 Broadway, NSW 2007, Australia \\ *Corresponding authors: H.K. Shon, tel: +61 29514 2629, e-mail: Hokyong.shon-1 @ uts.edu.au; L.D. Tijing, tel: \\ +6129514 2652, e-mail: leonard.tijing@uts.edu.au,
}

\section{Abstract}

In this study, we first revealed a "robbing behavior" during the immobilization of nZVI particles onto an electrospun polyacrylic acid (PAA)-polyvinyl alcohol (PVA) nanofiber mat. The robbing behavior can significantly reduce the number of nZVI particles immobilized onto the mat and hence weaken the performance of mitigating contaminated water. To minimize the undesirable effect of robbing behavior, we developed a dipping method that enables exposure of enough free Fe (II) as electron acceptors to the Fe (II)-complexed PAAPVA mat for the subsequent reduction. The result indicates that the mat with dipping can immobilize more than 1.7 times the weight percentage of nZVI particles for the mat without dipping. Moreover, the dipping method can also re-immobilize or enrich nZVI particles on the mat that has already partially immobilized nZVI particles. The nZVI-immobilized mat dipped once into the FeSO4 solution with a very little concentration $(0.32 \mathrm{~g} / \mathrm{L})$ had an excellent performance for trichloroethylene (TCE) degradation (more than 92\% TCE removed). Here, the developed dipping method shows great potential for nZVI immobilization and groundwater remediation.

Keywords: Robbing behavior; nZVI immobilization; Electrospun nanofiber; Dipping method; Re-immobilization 


\section{Introduction}

Nanoscale zero-valent iron (nZVI) particles with its strong reducing property and high reactivity [1] have been commonly used for the reduction of heavy metals (e.g. chromium [2] and arsenic) [3, 4] and halogenated organics (e.g. trichloroethylene (TCE) [5] and 4chlorphenol [6]) in the groundwater. Traditionally, nZVI particles are mixed in slurry and directly injected into the aquifer to remove contaminants [7]. However, during this process, nZVI particles are prone to agglomerate mutually or adsorbed onto soil grains, leading to a reduction of surface area [8]. Besides, these nZVI particles are too mobile to be distributed uniformly or to contact contaminated groundwater and may cause a secondary pollution downstream as well. Thus, to figure out a carrier, which can stably immobilize and uniformly distribute nZVI particles becomes necessary and practical.

Electrospining is a facile fabrication method which can fabricate fibers ranging from nanoscale to microscale $[9,10]$. As a result, the electrospun fiber has the advantages of controllable fiber size, high specific surface area and high porosity [11]. Another benefit is that different polymers can be fabricated together by electrospinning and hence the electrospun fibers can have certain properties from the selected polymers. This enables electrospun fibers to bond with nZVI particles and form nZVI-immobilized electrospun nanocomposites. Carboxylic group $(-\mathrm{COOH})$ is one of the main functional groups in polymer to bond with nZVI particles [12]. In order to achieve more stable and uniform nZVI immobilization, an in-situ immobilization method has been put forward [13, 14]. Briefly, polymer with - $\mathrm{COOH}$ can be electrospun into nanofiber mats and then soaked into Fe (II) or Fe (III) solution to allow the complexation between the $-\mathrm{COOH}$ and $\mathrm{Fe}$ ions. Then nZVI particles are directly generated on the mats by adding a reductant $\left(\mathrm{NaBH}_{4}\right.$ normally) and form the nZVI-immobilized electrospun polymer nanofiber mats. Some researchers have already managed to immobilize nZVI particles onto electrospun polymer nanofiber mats by the in- 
situ nZVI immobilization method [13, 15, 16]. Xiao et al. [13] first used the electrospun polyacrylic acid (PAA)-polyvinyl alcohol (PVA) nanofibers to immobilize nZVI and the fibers-supported nZVI showed superior decoloration capability to acid fuchsine solution. Ma et al. [15] also reported the use of electrospun PAA/PVA nanofiber mats to immobilize $\mathrm{Fe} / \mathrm{Pd}$ bimetallic nanoparticles, which significantly improved the degradation efficiency of TCE. Liu et al. [16] immobilized nZVI in the polyacrylonitrile (PAN)-based oxidized mat to reduce water contaminants (including methylene blue and TCE), which showed an excellent performance on the removal of each contaminant.

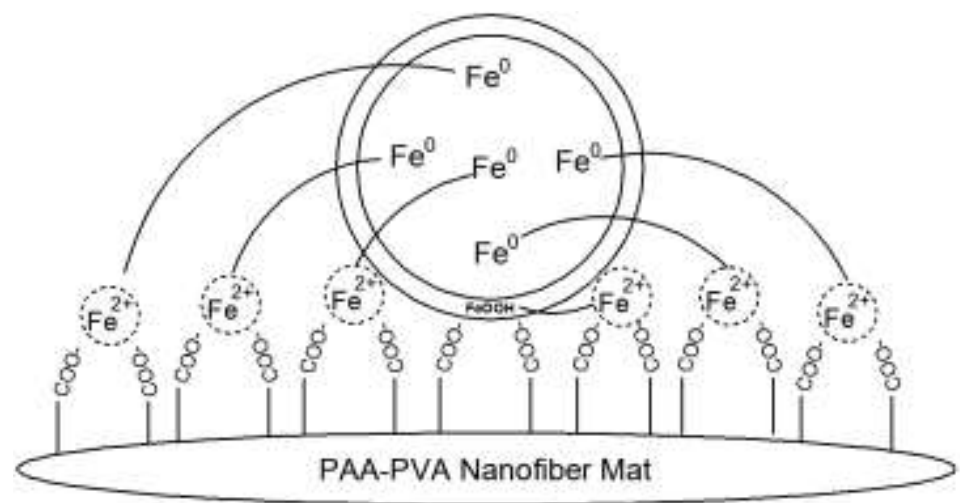

Figure 1. Assumption of the robbing behavior during the formation of nZVI.

However, by the in-situ immobilization method, all the Fe (II) ions come from the bonded-Fe on the nanofibers. The size of nZVI particles ranges from around $10 \mathrm{~nm}$ to 100 nm [17] (much bigger than the size of Fe ion), which means that to form one nZVI nanoparticle requires more than thousands of Fe ions as the electron acceptors. Therefore, as shown in Fig. 1, we presume that there must be a "robbing behavior" that one of the Fe (II) / $\mathrm{Fe}$ (III) ions was first reduced to $\mathrm{Fe}(0)$ and then robbing other Fe ions from adjacent $-\mathrm{COO}-$ Fe to generate nZVI particles to a critical size. Therefore, not each reaction site with -COOFe can generate nZVI particles; most of Fe ions have to sacrifice themselves for the preliminary formed $\mathrm{Fe}(0)$ and together crystalize to form larger nZVI particles. To minimize the "robbing behavior" and form as many nZVI particles as possible on their own original 
sites, we come up with a dipping method, i.e., dipping the electrospun nanofiber mat into $\mathrm{Fe}$ (II) or Fe (III) solution again to offer enough free Fe ions to the $-\mathrm{COO}-\mathrm{Fe}$ reaction sites (Fig. 2a). In this case, during the crystallization of nZVI particles, the -COO-Fe will get electron acceptors from the ambient free Fe ions rather than robbing from the adjacent bonded-Fe.

(a)

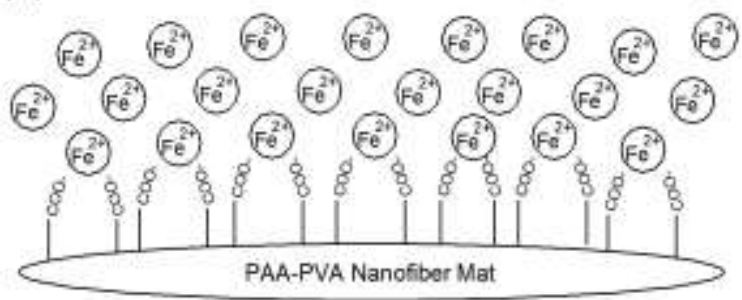

(b)

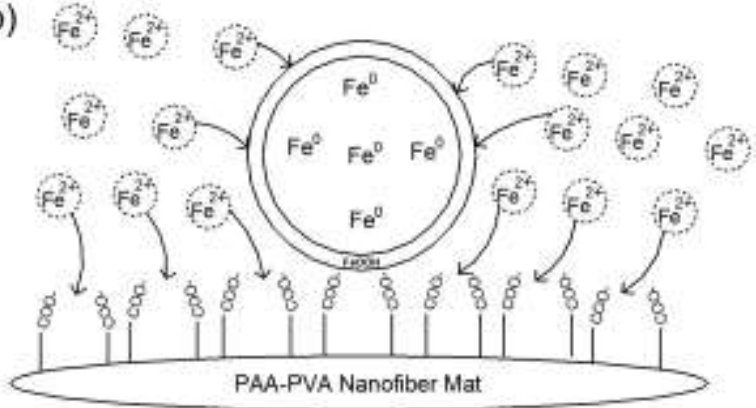

Figure 2. Dipping approach (a) to minimize robbing behavior and (b) to re-immobilize nZVI particles on polymeric nanofiber mat.

From another perspective, while the robbing behavior is happening, the adjacent COOFe bonding is also broken and hence the $-\mathrm{COOH}$ will be available again. Consequently, it is possible for those $-\mathrm{COOH}$ groups to complex with new Fe ions and re-immobilize new nZVI particles on the nanofibers again (Fig. 2b). According to this assumption, we believe that, after the initial immobilization, a re-immobilization process can be achieved if there are extra Fe ions exposed to the electrospun polymer mat. Thus, the dipping method can also be used for the re-immobilization of nZVI particles on the mat that has already but not entirely immobilized nZVI particles.

In this study, our objective was to have a better understanding of nZVI immobilization mechanism and produce a well-performed nZVI-immobilized mat for the TCE degradation. Specifically, we try to reveal the "robbing behavior" during the nZVI immobilization and then develop a dipping method to control the "robbing behavior". Mats with various dipping 
conditions were characterized by SEM, EDS, FTIR, TGA and BET to see the immobilization of nZVI particles and their performances of TCE degradation were also tested.

\section{Materials \& Methods}

\subsection{Materials}

Polyacrylic acid (PAA, Mw = 2,000), polyvinyl alcohol (PVA, 87-89\% hydrolyzed, $\mathrm{Mw}=85,000-124,000)$, ferrous sulphate heptahydrate $\left(\mathrm{FeSO}_{4} \cdot 7 \mathrm{H}_{2} \mathrm{O}\right)$, sodium borohydride $\left(\mathrm{NaBH}_{4}\right)$, trichloroethylene (TCE), and n-hexane were all purchased from Sigma-Aldrich. Deionized (DI) water from a Millipore Milli-Q water system was used; all the oxygen-free water was prepared by purging nitrogen gas for $10 \mathrm{~min}$ to remove the dissolved oxygen and avoid the oxidation of the nZVI. All chemicals were used as received without any modification.

\subsection{Solution preparation}

In this study, the concentration of PVA was prepared at $14 \mathrm{wt} \%$ while the neat PAA solution was prepared at $46 \mathrm{wt} \%$ to make the molar ratio of PAA twice as PVA.

All the PVA solutions were prepared by dissolving PVA into DI water stirring at $90^{\circ} \mathrm{C}$ until completely dissolved, and then cooled down to room temperature. Meanwhile, PAA solutions were prepared by dissolving PAA into a mixed solvent composed of DI water at room temperature with magnetic stirring overnight.

To prepare the blended solution (PAA/PVA), each solution was first stirred individually for 30 min and then the PAA was poured over the PVA solution and continued stirring for $24 \mathrm{~h}$ to ensure proper mixing. The blended mass of each PAA solution was identical with that of each PVA solution. 


\subsection{Electrospinning and cross-linking of PAA/PVA nanofiber mats}

The electrospinning set-up is shown in Fig. 3. Nanofibers were directly fabricated onto a rotating drum collector covered with baking paper in a sealed chamber same as our previous study [18]. Electrospun PAA/PVA mat was fabricated at an employed voltage of 12 $\mathrm{kV}$. The tip-to-collector distance (TCD) was $15 \mathrm{~cm}$ and the feed flow rate was controlled at $0.5 \mathrm{ml} / \mathrm{h}$ by a syringe pump.

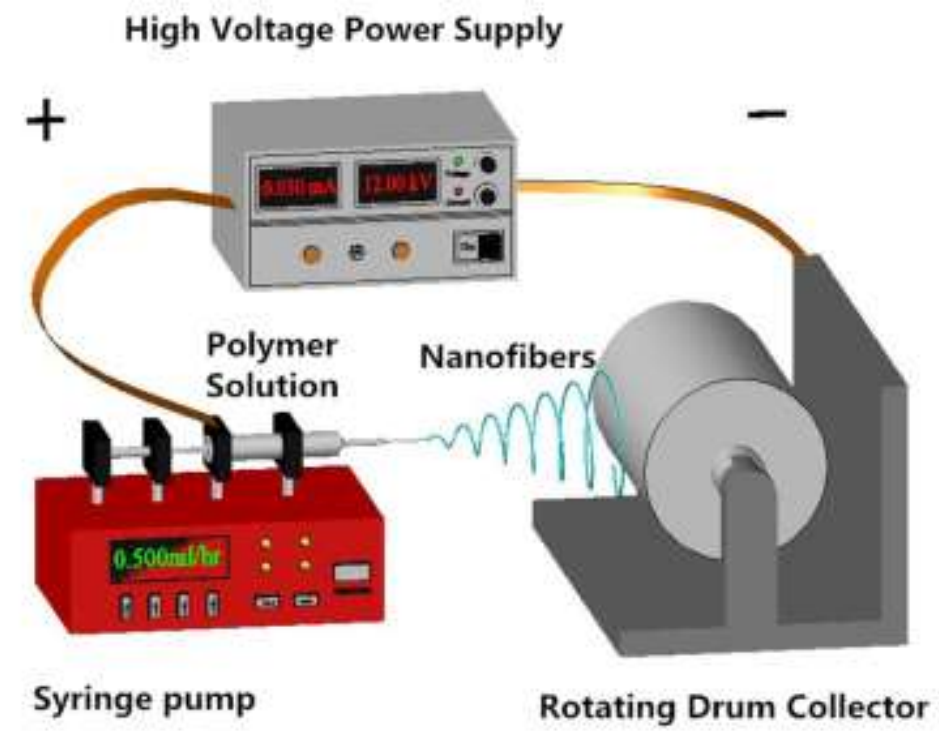

Figure 3. Schematic diagram of the electrospinning configuration

The polymer solution was supplied by a $12 \mathrm{ml}$ syringe attached with a needle $(21 \mathrm{G}$, inner diameter $=0.51 \mathrm{~mm}$ ) connected via a metallic adaptor. The electrospinning was processed in a sealed chamber where the relative humidity was maintained at $30 \sim 40 \%$ by using silica gel. After fabricating for $10 \mathrm{~h}$, as-spun mat was put into a dry oven at $60^{\circ} \mathrm{C}$ for 1 day to remove the residual solvent [18]. Then, the dried PAA/PVA mat was cross-linked by thermal treatment in an oven at $145^{\circ} \mathrm{C}$ for 20 min to make them water-stable [19]. 


\subsection{Synthesis and immobilization of nanoscale zero valent iron (nZVI)}

After thermal treatment, the cross-linked mat was soaked into $0.1 \mathrm{~mol} / \mathrm{L} \mathrm{FeSO}_{4}$ solution for $6 \mathrm{~h}$ to allow the complexation of $\mathrm{Fe}$ (II) ions and the rest of free $-\mathrm{COOH}$ groups from PAA. To understand the effects of Fe (II) ions supply on the formation and immobilization of nZVI particles into/onto the mat, two groups of experiments were conducted simultaneously: rinsed and unrinsed approaches. As shown in Fig. 4, for group 1 (rinsed approach - upper schematic in Fig. 4), the soaked mat was rinsed by oxygen-free DI water 3 times to remove the ambient $\mathrm{Fe}$ (II) ions from the surface and then $0.4 \mathrm{~mol} / \mathrm{L} \mathrm{NaBH} 4$ solution at $2 \mathrm{~mL} / \mathrm{min}$ flow rate was slowly in an anaerobic chamber (filled by nitrogen gas) to form and immobilize nZVI particles. The reaction is shown below [20]:

$$
\mathrm{Fe}^{2+}+2 \mathrm{BH}_{4}^{-}+6 \mathrm{H}_{2} \mathrm{O} \rightarrow \mathrm{Fe}^{0} \downarrow+2 \mathrm{~B}(\mathrm{OH})_{3}+7 \mathrm{H}_{2} \uparrow
$$

After reacting for $2 \mathrm{~min}$, mat was cut into 2 equal pieces (R0 and R1). For R0 (i.e., without dipping), we kept adding $\mathrm{NaBH}_{4}$ solution for another 4 min while for $\mathrm{R} 1$, the sample was first dipped into $0.1 \mathrm{~mol} / \mathrm{L} \mathrm{FeSO}_{4}$ solution once and then $\mathrm{NaBH}_{4}$ solution was again added for 4 min. For group 2 (unrinsed approach - lower schematic in Fig. 4), similar process was carried out in preparing the mats as with those of group 1, but this time, the soaked mat was not rinsed with oxygen-free DI water. In this case, the mat surface could still remain a large number of free Fe (II) ions as electron acceptors for the subsequent reduction. Similar with R0 and R1, U0 was the mat without dipping and U1 was the mat with dipping. Additionally, to figure out the effect of dipping times on the nZVI immobilization, we also prepared a sample U2 which took another dipping (totally twice) in the middle of the 4 min reaction from U1. Finally, all the nZVI-PAA/PVA mats were rinsed by ethanol and stored in a sealed glass bottle, which was filled with nitrogen gas. 


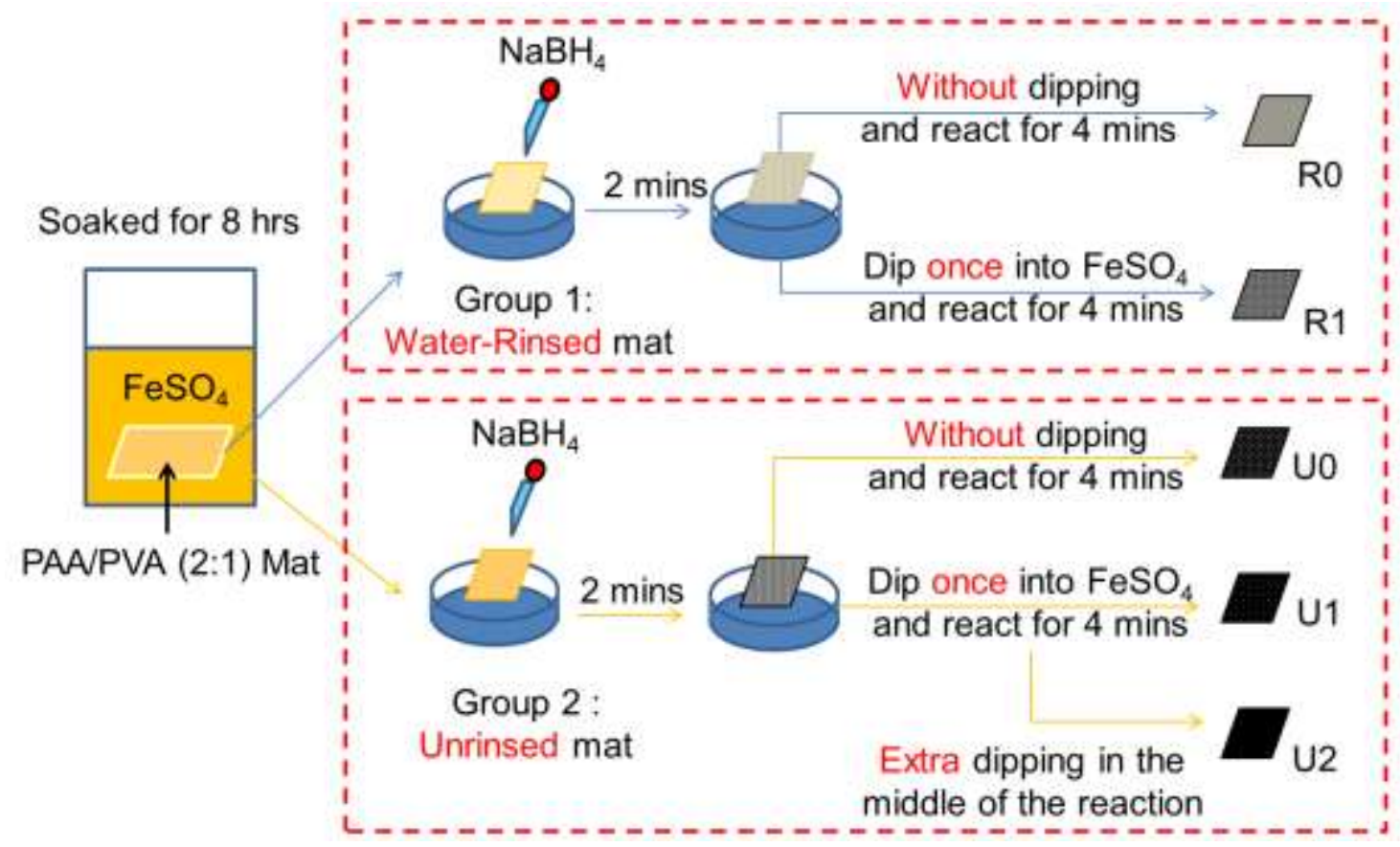

Figure 4. Schematic diagram of the nZVI particles growth and re-immobilization

\subsection{Characterization and measurements}

2.5.1 Scanning electron microscopy (SEM) and energy-dispersive X-ray spectroscopy (EDS)

The surface morphology of all the mats was observed by scanning electron microscopy and energy dispersive X-ray spectrometry (SEM and EDS, Zeiss Supra 55VP, Carl Zeiss AG). Samples taken from each mat were coated by Au/Pd prior to SEM. The SEM images were carried out at an accelerating voltage of $10 \mathrm{kV}$, and multiple image magnifications at various areas were obtained for each sample [18]. All the nZVI particle sizes and distributions on the nanofiber mat were calculated and analyzed by Image $\mathrm{J}$.

\subsubsection{Thermo-gravimetric analysis}

Thermo-gravimetric analysis (TGA) was carried out on Discovery TGA thermogravimetric analyzer (SDT-Q600, United States) from $50^{\circ} \mathrm{C}$ to $600^{\circ} \mathrm{C}$ at a heating rate of $10^{\circ} \mathrm{C} / \mathrm{min}$ in $\mathrm{N}_{2}$ atmosphere. The crucible material was platinum (PN: 960149.901, United States). Each sample was dried by purging $\mathrm{N}_{2}$ for $1 \mathrm{~min}$ before measurement. 
Each sample was analyzed by attenuated total reflectance Fourier transform infrared spectroscopy (ATR-FTIR) via Paragon 1000 Spectrometer (PerkinElmer, USA) in the range of $600-4000 \mathrm{~cm}^{-1}$ with a signal resolution of $1 \mathrm{~cm}^{-1}$ and a minimum of 32 scans.

\subsubsection{Brunauer Emmett Teller (BET)}

N2 adsorption-desorption isotherms were collected on a Micromeritics 3Flex analyzer at the testing temperature of $77 \mathrm{~K}$. Brunauer-Emmett-Teller (BET) analysis was used to determine the surface area and was calculated using the isothermal points at a relative pressure of $\mathrm{P} / \mathrm{P} 0=0.05-0.25$.

\subsection{Dechlorination of nZVI-PAA/PVA nanofiber mat}

TCE is a typical chloride organic, usually selected to test the dechlorination capacity of nZVI-PAA/PVA nanofiber mats. In this study, each mat was soaked in $25 \mathrm{~mL}$ of $20 \mathrm{mg} / \mathrm{L}$ TCE solution and the bare weight of each mat (before soaking in the $\mathrm{FeSO}_{4}$ solution) in the TCE solution was kept at $8 \mathrm{mg}(0.32 \mathrm{~g} / \mathrm{L})$. After shaking at $100 \mathrm{rad} / \mathrm{min}$ for $0.5,1,2$ and $4 \mathrm{~h}$ on a platform mixer, $2 \mathrm{~mL}$ supernatant liquid sample was respectively withdrawn and transferred to a new vial for the subsequent liquid-liquid extraction. The n-hexane was used to extract TCE from water. The concentration of the extracted TCE solution was measured by GC-MS-TQ8040 (Shimadzu, Japan). The dechlorination efficiency was calculated using the following equation:

$$
\text { Dechlorination efficiency }(\%)=\frac{c_{\text {int }}-c_{\text {end }}}{c_{\text {int }}} \times 100 \%
$$

where, $\mathrm{C}_{\mathrm{int}}$ and $\mathrm{C}_{\mathrm{end}}$ are the initial and the final TCE concentrations, respectively. 


\section{Results and discussion}

\subsection{SEM}

All the SEM images, particle size distribution and corresponding growth models of the five nZVI-decorated mats are shown in Fig. 5. It is clear that nZVI particles were fully and uniformly distributed on all the five mats (R0, R1, U0, U1 and U2). R0 (Fig. 5a) was rinsed by oxygen-free DI water before being added with $\mathrm{NaBH}_{4}$ solution. The generated nZVI particles were much less than those on the unrinsed U0 (Fig. 5c), which was consistent with the assumed mechanism shown in Fig. 1. At the very beginning, there was no free Fe (II) ion exposed to the fiber surface, and thus the first formed crystal nucleus had to rob Fe (II) ions from the adjacent COO-bonded Fe (II) to grow itself. This robbing behavior was probably driven by the Ostwald ripening process [21]. It is noted that after the breaking of COO-Fe bonding, those adjacent carboxylic groups had become non-complexed and available to bond new Fe (II), which made the mat possible to proceed with the subsequent re-immobilization process. As shown in Fig. 5b, R1 was the parallel group (for R0) which was dipped once into the growth solution during the middle of reduction process. It is observed that the number of nZVI particles on R1 was more than that on R0. Meanwhile, the average diameter of R1 (118 $\pm 70 \mathrm{~nm})$ was just a bit bigger than R0 $(94 \pm 34 \mathrm{~nm})$ but the range of particle size distribution of R1 were much wider than that of R0. This is probably because the original nZVI particles grew to a larger size while the new nZVI particles were also re-immobilized on the fiber with a smaller size.

Compared with R0 and R1, obviously, there were more and denser nZVI particles immobilized onto U0, U1 and U2. The average particle sizes of the three mats were $91 \pm 26$ $\mathrm{nm}, 84 \pm 26 \mathrm{~nm}$ and $211 \pm 26 \mathrm{~nm}$ respectively. For U0 (Fig. 5c), the majority of nZVI 
particles were attached on the surface of fibers and the diameter of the particles were mainly ranging from $60 \mathrm{~nm}$ to $120 \mathrm{~nm}$.

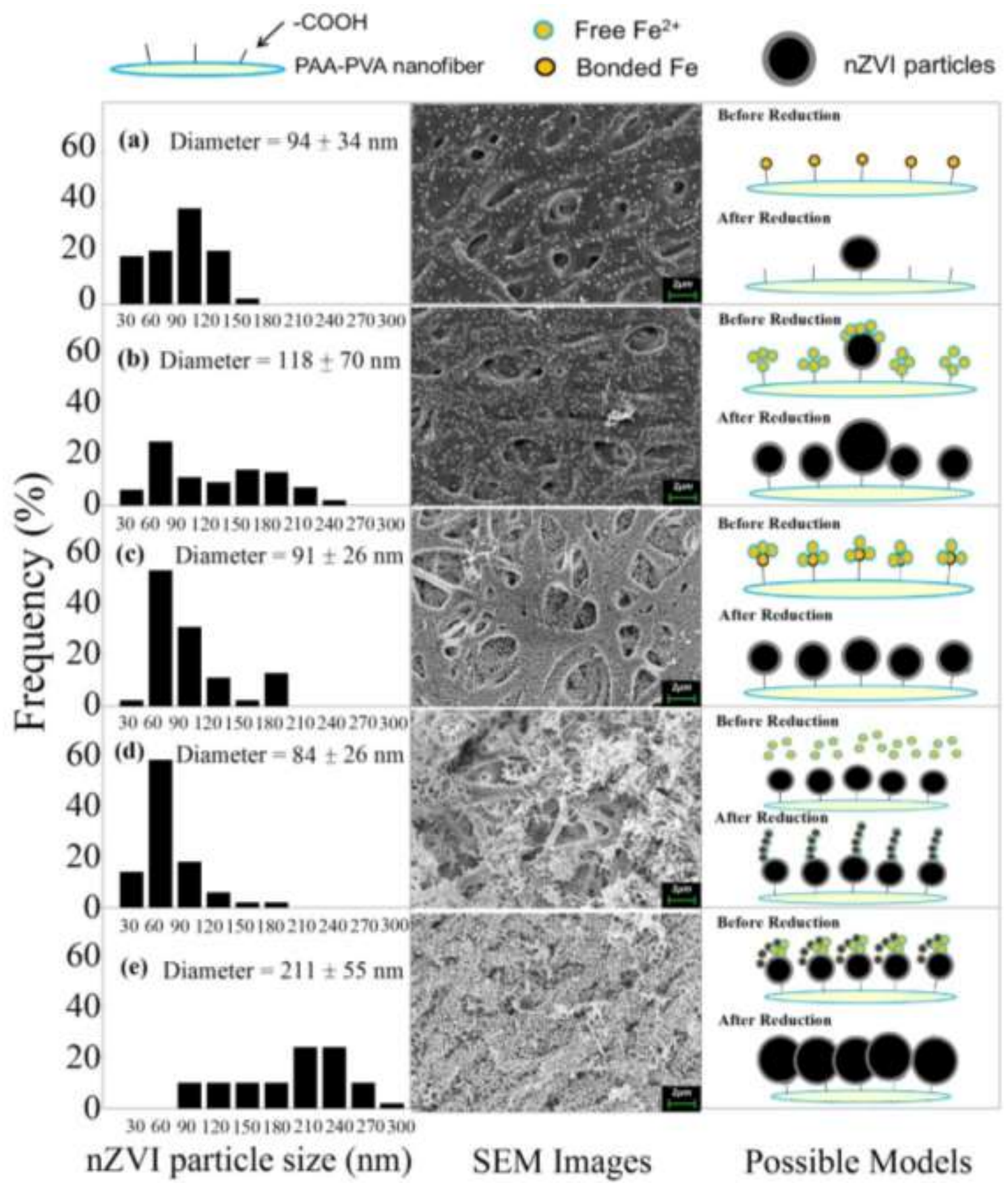

Figure 5. SEM images, nZVI particle size distribution and proposed nZVI growth mechanism of (a) R0, (b) R1, (c) U0, (d) U1 and (e) U2.

After dipping once into the growth solution, nZVI particles (U1, Fig. 5d) sprouted out of the fiber surface and formed a coral-like structure with the fibers. The sprouted branches of the 
coral-like structure were just like the chain-like structure of the gathered free nZVI particles [21]. This indicates that the nZVI particles on the chain were reduced to be individual particles first and then joint together forming a chain-like structure. The average diameter of nZVI particles was a little bit smaller than that of U0, possibly because the particles on chainlike branches of the coral structure were a little smaller than those on the surface. Both U0 and U1 had average particle diameters lower than $100 \mathrm{~nm}$ and their standard deviations were quite the same at around $26 \mathrm{~nm}$. In contrast, for U2 (Fig. 5e), the average diameter of nZVI particles increased dramatically, more than twice the figures for U0 and U1, which may significantly reduce the effective surface area exposed to contaminants [22]. After the second dipping, great changes took place in the morphology of fiber surface. It is obvious that the number of nZVI particles increased and the fibers were fully covered by nZVI particles, leading to a thicker nZVI-decorated fiber size. Compared with U0 and U1, pores and voids among the fibers of U2 were fully covered by the over-dense/-sized nZVI particles. This may lead to a reduction in the effective surface area.

\subsection{EDS}

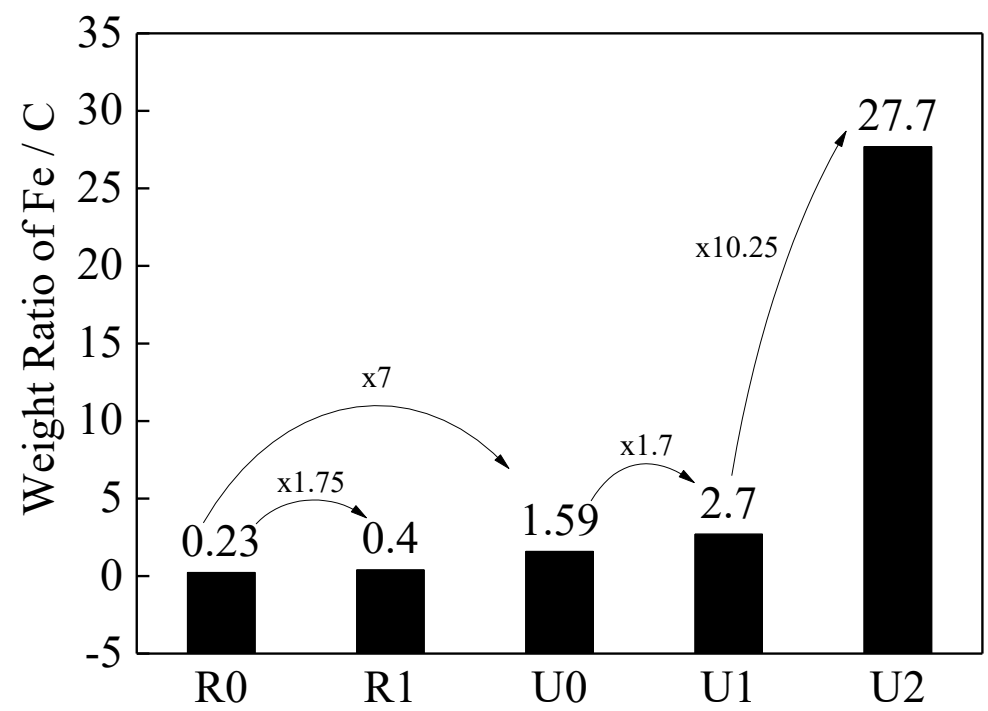

Figure 6. The weight ratio of $\mathrm{Fe} / \mathrm{C}$ on the five mats. 
The EDS results (Fig. 6) were consistent with the SEM images. The Fe/C ratios of R0 (0.23) and R1 (0.4) were both lower than 1 , which means that, on R0 and R1, the majority of the area of the mat surface was still PAA-PVA fibers rather than nZVI particles. By dipping once into the growth solution, $\mathrm{R} 1$ had 1.75 times higher $\mathrm{Fe} / \mathrm{C}$ ratio than that of $\mathrm{R} 0$. Compared with R0, U0 was initially exposed to growth solution and obtained 7 times in Fe/C ratio (at 1.59) than R0, which indicated that exposure to the Fe (II) growth solution had a great contribution to nZVI immobilization. For U1, the Fe/C ratio was 2.7, which was 1.7 times higher than that for U0. The results indicated that during the reduction process, supplying more Fe (II) ions can also have a positive effect on the growth of nZVI particles. Interestingly, after the second dipping, the $\mathrm{Fe} / \mathrm{C}$ ratio increased dramatically, even more than 10 times than the figure for U1. This may be caused by the R1 coral-like structure which offered more surface area and sites for nZVI particles growth. It is noted that both R0 and U0, after dipping once into the growth solution, got a similar rate of increase of around 1.7 times. Thus, in terms of the EDS results, nZVI growth rate was similar with the nZVI immobilization rate.

\subsection{TGA}

TGA was used to characterize the loading capacity of immobilized nZVI particles on the cross-linked PAA/PVA nanofiber mats (Fig. 7). There was a slight weight loss on each mat upon heating up to $170^{\circ} \mathrm{C}$, which should be due to the evaporation of ethanol and the loss of moisture in the mats [15]. Afterwards, the major weight loss of nZVI-immobilized mats at the region from 170 to $500^{\circ} \mathrm{C}$ is attributed to the decomposition of the PAA/PVA polymers. However, there were three stages during the decomposition [23]. On stage one, from 170 to $220^{\circ} \mathrm{C}$, it was due to the dehydration of PAA with anhydrides formation [24]; On stage two, from 230 to $400^{\circ} \mathrm{C}$, it is attributed to the decomposition of anhydride, $-\mathrm{OH}$ and $-\mathrm{COOH}$ groups [25]; On stage three, from 400 to $500^{\circ} \mathrm{C}$, there was a sharp weight decrease on each 
mat, which was probably due to the decomposition of esters. The percentage of R0 weight plunged most, which indicated that R0 had the highest ratio of polymer. When it comes to $600^{\circ} \mathrm{C}$, all the polymeric nanofibers had been burned out, leaving nZVI particles as the residual mass. Consistently, R0 remained the least nZVI particles at around $23 \mathrm{wt} \%$ while the R1 was at 36\%, 1.6 times the amount for R0. This result was consistent with EDS result. However, the weight percentage of U0 at $36 \%$ was only 1.7 times as much as R0. Besides, the weight of nZVI particles on U1 (46\%) was $10 \%$ higher than U0 but only $4 \%$ lower than U2. It is probably because the nZVI particles on U2 were mainly immobilized on the external surface of the mat and form a barrier for the internal nZVI immobilization. Nevertheless, it is confirmed that more nZVI particles were formed and attached onto the mat by the dipping method. By contrast, all the mats with the dipping method were successfully immobilized more than twice the weight of nZVI particles than those in other research [15].

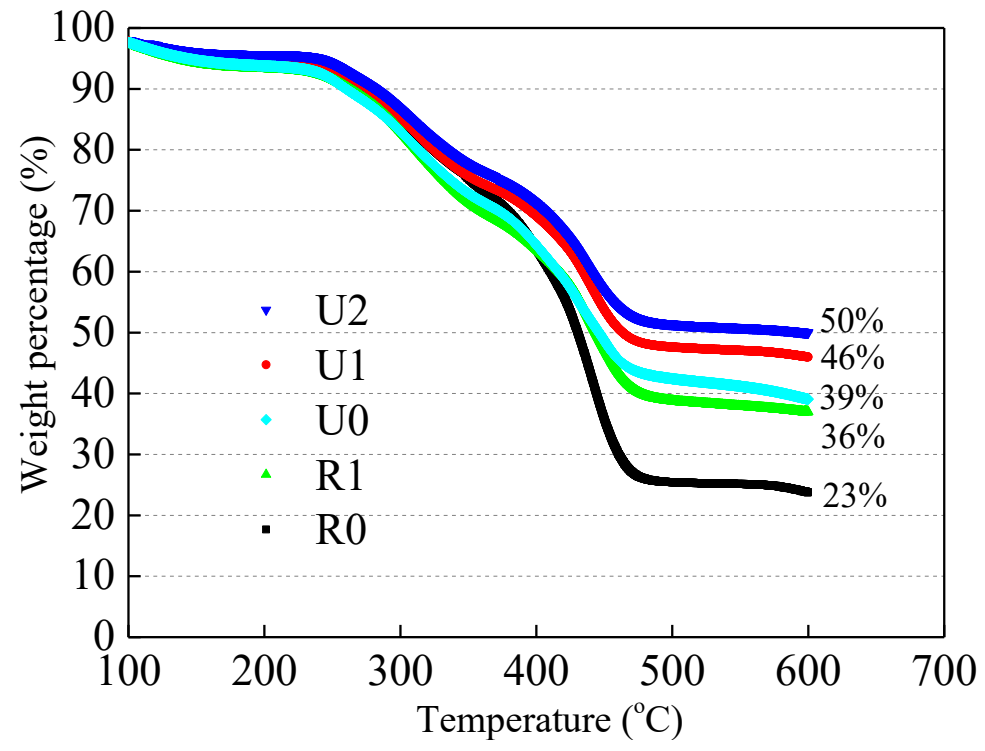

Figure 7. The weight percentage of the five nZVI- immobilized mats

\subsection{FTIR}

The FTIR result is illustrated in Fig. 8. The peak of PAA-Fe is at $1385 \mathrm{~cm}^{-1}$ [26] for each mat, there was a sharp peak at this wavelength, which indicates the immobilization of nZVI 
particles. The intensity of U2 was quite similar with U1, although the nZVI particles on the U2 were more than those on U1. This could be explained by limited number of $-\mathrm{COOH}$ on the mat. Most nZVI particles on U2 were bonded on the adjacent nZVI particles rather than on the fiber surface directly. In contrast, the intensities of this peak on the U0, R0 and R1 were obviously lower than U1 and U2, indicating lower nZVI particles loaded on the mat. Meanwhile, there is a sharp peak at $614 \mathrm{~cm}^{-1}$ in each mat, attributed to the Fe-O transverse vibration [27], which proves the existence of FeOOH shell. The FTIR result is also consistent with the results discussed in former the sections.

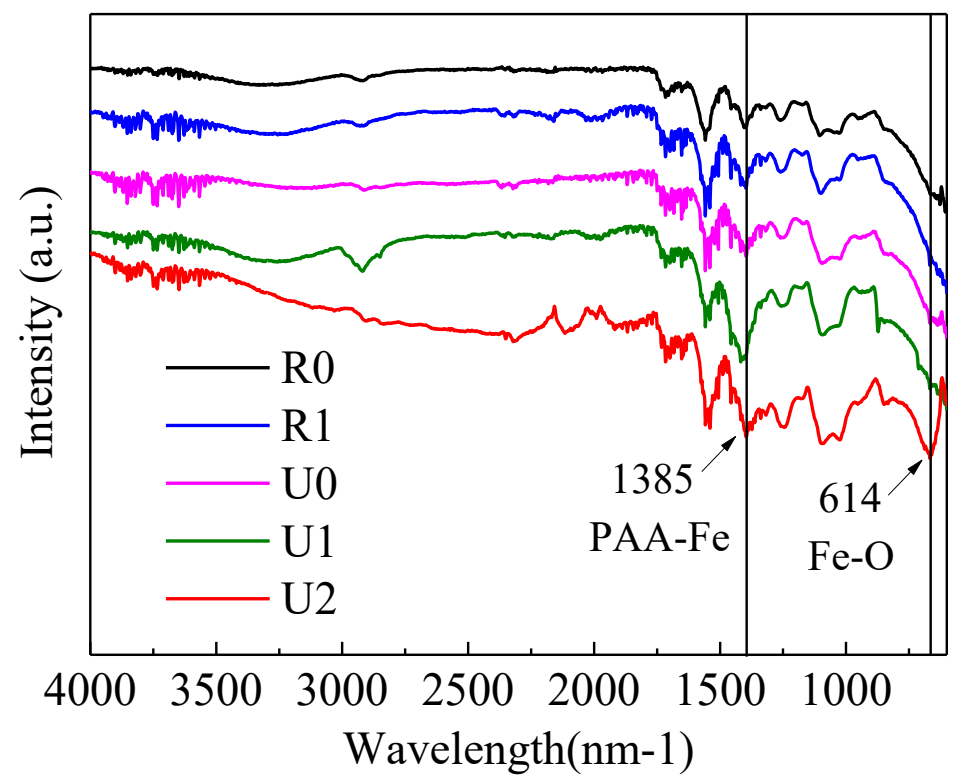

Figure 8. The FTIR results of the five nZVI- immobilized mats

\subsection{BET}

Nitrogen adsorption/desorption analysis was used to further characterize the five nZVIimmobilized mats (R0, R1, U0, U1 and U2). As shown in Fig. 9, both the neat mat and the nZVI-immobilized mats represent typical isotherms between type II and III with hysteresis loops between type $\mathrm{H} 3$ and $\mathrm{H} 4$. A sharp adsorption increase shows at a high relative pressure of $0.9-0.99$, representing the existence of the numerous meso- and macro-pores in samples [28]. The specific surface areas and pore volume of nZVI-immobilized mats were obviously higher than the neat mat, which means nZVI particles had a great contribution to the surface area. Also, the specific surface areas and pore volume of the three unrinsed mats were higher 
than those of the rinsed mats. This is consistent with the amount of the nZVI particles immobilized on the mats. U1 had the highest specific surface area and pore volume at 14.59 $\mathrm{m}^{2} / \mathrm{g}$ and $0.0429 \mathrm{~cm}^{3} / \mathrm{g}$, around twice and 2.5 times greater than those of R0. Although U2 immobilized the most amount of nZVI particles, it had a lower specific surface area $(9.83$ $\mathrm{m} 2 / \mathrm{g})$ and pore volume $(0.0186 \mathrm{~cm} 3 / \mathrm{g})$ than $\mathrm{U} 0$ and $\mathrm{U} 1$. This could be explained by the pore blocking and mutual overlap from those over-dense/-sized nZVI particles as we observed in Fig. 5e. Generally, in terms of specific surface areas and pore volume, U1 had a better performance among the five nZVI-immobilized mats.

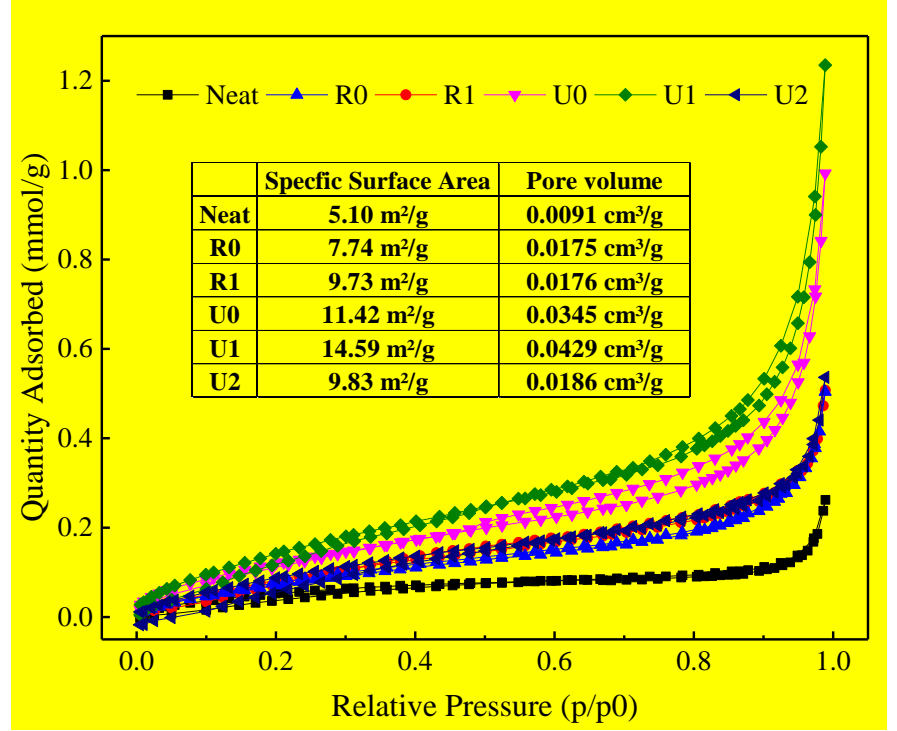

Figure 9. BET surface area and pore volume analysis of the five nZVI- immobilized mats

\subsection{TCE Removal}

The dechlorination performance of each nZVI-immobilized mat is illustrated in Fig. 10. All the dechlorination rates increased with time but their growth rates decreased. Over $4 \mathrm{~h}$ reaction, the neat PAA-PVA mat as a blank sample had the lowest dechlorination rate increase from $1.5 \%$ to $5.4 \%$. At the first $30 \mathrm{~min}$, U0 had a higher dechlorination rate than $\mathrm{U} 1$, probably because the TCE solution was not fully infiltrated into the voids of U1 and not all the nZVI particles had been exposed to the TCE contaminants. Since the first hour, the rate of U1 surpassed U0 obtaining the highest degradation rate of $92 \%$ after $4 \mathrm{~h}$ of reaction. In contrast, the dechlorination rate of R0 was also a little bit higher than that of R1 in the first 30 min, while this is more likely due to a smaller nZVI particle size on R0 mat. After the first 30 
min, the dechlorination rate of $\mathrm{R} 1$ surpassed the rate of $\mathrm{R} 0$. This can be explained by the consumption of nZVI particles. The nZVI particles on R0 with a smaller size rapidly reacted with TCE, but its amount was apparently less than R1. Thus, after $30 \mathrm{~min}$, most of the outer nZVI particles on R0 had been consumed and then the reaction rate reduced. Interestingly, U2 obtained the lowest dechlorination rate except for the $4^{\text {th }}$ hour. This is probably because the oversized nZVI particles on U2 had a lower surface area and apparently blocked the voids between nanofibers as well. This was also proved by the BET results. In this case, although U2 immobilized the highest weight percentage of nZVI particles, those particles cannot effectively contact contaminants, thereby leading to a lower removal. On the other hand, after $4 \mathrm{~h}$, the outermost nZVI particles had been consumed and more nZVI particles and interfaces were then exposed to the contaminants. As a result, $\mathrm{U} 2$ exceeded R0 and R1 and achieved a higher dechlorination rate at $87 \%$. From this perspective, nZVI with a larger particle size may also have some potential in long period remediation.

In this study, the unrinsed mat with once dipping had the best removal at $92 \%$, which not only had a $20 \%$ higher removal to TCE solution with twice higher concentration but also used only half mass of the nZVI-immobilized mat than the result in previous research [15]. Therefore, the dipping method could be an effective method that can be employed in nZVI immobilization for the mitigation of nZVI-target contaminants. 


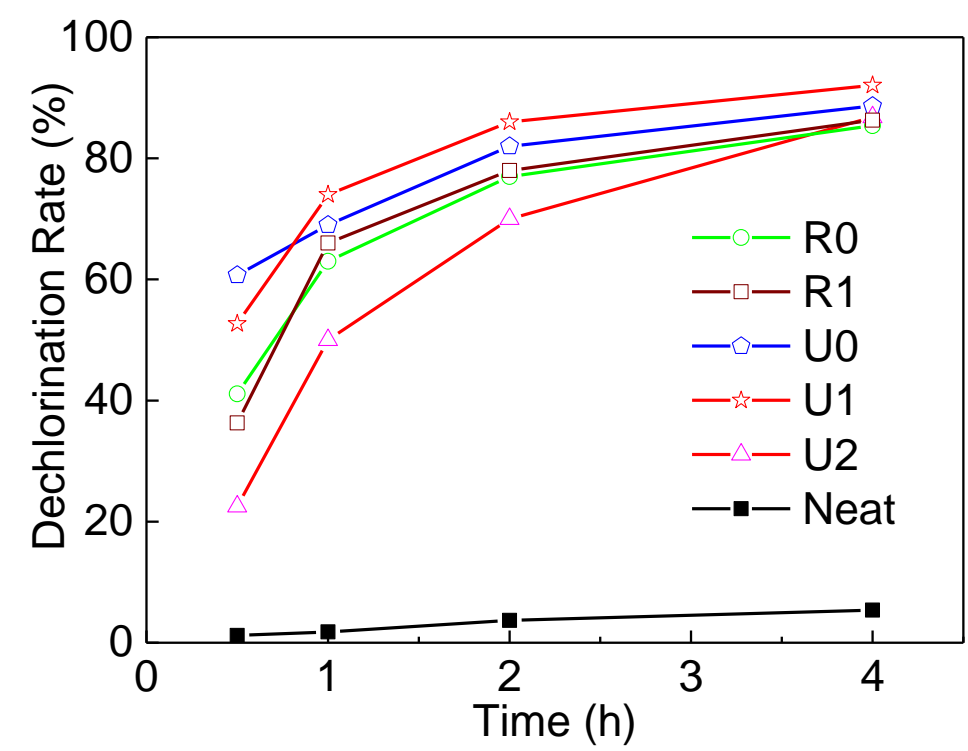

Figure 10. The TCE dechlorination rates of the five nZVI- immobilized mats

\section{Conclusions}

In this study, we first revealed a "robbing behavior" phenomenon wherein the first formed nZVI crystal nucleus would rob adjsacent Fe from the carboxylic-complexed Fe on crosslinked nanofibers during the immobilization of nZVI particles. According to this phenomenon, we came up with a dipping method which can either minimize "robbing behavior" for the sake of a better immobilization, or offer a feasible re-immobilization process for the insufficiently nZVI-immobilized electrospun nanofiber mat. The main conclusions are listed as below:

The "robbing behavior" will likely happen during the nZVI immoblization if there is not enough free Fe (II) exposed to the carboxyl-bonded Fe (II).

The water-rinsed Fe (II)-PAA-PVA mat would immobilize less nZVI particles than the unrinsed mat, because robbing behavior led to a considerable decrease of immobilization sites.

Mats undergoing robbing behavior are possible to re-complex Fe (II) and re-immobilize / grow nZVI particles onto the electrospun nanofiber PAA-PVA mat by dipping into Fe (II) 
solution, because the initial bonding between carboxylic group and Fe (II) was broken, and then the carboxylic group became available again to complex new free Fe (II).

Multiple dipping times during the reduction of Fe (II) to nZVI can effectively increase the number of nZVI particles immobilized on the mat, but excess dipping times can generate oversized nZVI particles, which can reduce the specific surface area of nZVI particles and the permeability of the electrospun nanofiber mat, and consequently cause a lower dechlorination rate to TCE.

In this study, U1 (unrinsed and dipped once into Fe (II) solution) had the highest dechlorination rate at $92 \%$ due to the second highest amount of nZVI particles immobilized on the mat and a relatively smaller particle size.

Briefly, this paper gives a better understanding of the nZVI immobilization mechanism and the correspondingly developed dipping method had great potential in the application of nZVI immobilization for the nZVI-targeted contaminants remediation.

\section{Acknowledgement}

This research was funded by the Cooperative Research Centre for Contamination Assessment and Remediation of the Environment (CRC CARE, Project No. 4.1.18-13/14). We also appreciate our discussions with Dr. Dawei Su from the Faculty of Science at the University of Technology Sydney.

\section{References}

[1] J. Ma, D. He, R.N. Collins, C. He, T.D. Waite, The tortoise versus the hare-Possible advantages of microparticulate zerovalent iron (mZVI) over nanoparticulate zerovalent iron (nZVI) in aerobic degradation of contaminants, Water Research 105 (2016) 331-340. 
[2] R. Fu, X. Zhang, Z. Xu, X. Guo, D. Bi, W. Zhang, Fast and highly efficient removal of chromium (VI) using humus-supported nanoscale zero-valent iron: Influencing factors, kinetics and mechanism, Separation and Purification Technology, 174 (2017) 362-371.

[3] Y. Zou, X. Wang, A. Khan, P. Wang, Y. Liu, A. Alsaedi, T. Hayat, X. Wang, Environmental remediation and application of nanoscale zero-valent iron and its composites for the removal of heavy metal ions: a review, Environmental Science \& Technology 50 (2016) 7290-7304.

[4] S. Li, W. Wang, F. Liang, W.-x. Zhang, Heavy metal removal using nanoscale zerovalent iron (nZVI): theory and application, Journal of hazardous materials 322 (2017) 163 171.

[5] T. Phenrat, T. Thongboot, G.V. Lowry, Electromagnetic induction of zerovalent iron (ZVI) powder and nanoscale zerovalent iron (NZVI) particles enhances dechlorination of trichloroethylene in contaminated groundwater and soil: Proof of concept, Environmental science \& technology 50 (2015) 872-880.

[6] Q. Ma, H. Zhang, X. Deng, Y. Cui, X. Cheng, X. Li, M. Xie, Q. Cheng, B. Li, Electrochemical fabrication of NZVI/TiO 2 nano-tube arrays photoelectrode and its enhanced visible light photocatalytic performance and mechanism for degradation of 4-chlorphenol, Separation and Purification Technology, (2017).

[7] D. O’Carroll, B. Sleep, M. Krol, H. Boparai, C. Kocur, Nanoscale zero valent iron and bimetallic particles for contaminated site remediation, Advances in Water Resources 51 (2013) 104-122.

[8] I. Dror, O.M. Jacov, A. Cortis, B. Berkowitz, Catalytic transformation of persistent contaminants using a new composite material based on nanosized zero-valent iron, ACS applied materials \& interfaces 4 (2012) 3416-3423. 
[9] D. Li, Y. Xia, Electrospinning of nanofibers: reinventing the wheel?, Advanced materials 16 (2004) 1151-1170.

[10] L.D. Tijing, Y.C. Woo, M.A.H. Johir, J.-S. Choi, H.K. Shon, A novel dual-layer bicomponent electrospun nanofibrous membrane for desalination by direct contact membrane distillation, Chemical Engineering Journal 256 (2014) 155-159.

[11] S.-J. Kang, L.D. Tijing, B.-s. Hwang, Z. Jiang, H.Y. Kim, C.S. Kim, Fabrication and photocatalytic activity of electrospun nylon-6 nanofibers containing tourmaline and titanium dioxide nanoparticles, Ceramics International 39 (2013) 7143-7148.

[12] Y. Bagbi, A. Sarswat, S. Tiwari, D. Mohan, A. Pandey, P.R. Solanki, Synthesis of 1cysteine stabilized zero-valent iron (nZVI) nanoparticles for lead remediation from water, Environmental Nanotechnology, Monitoring \& Management 7 (2017) 34-45.

[13] S. Xiao, M. Shen, R. Guo, S. Wang, X. Shi, Immobilization of zerovalent iron nanoparticles into electrospun polymer nanofibers: synthesis, characterization, and potential environmental applications, The Journal of Physical Chemistry C 113 (2009) 18062-18068. [14] S. Xiao, H. Ma, M. Shen, S. Wang, Q. Huang, X. Shi, Excellent copper(II) removal using zero-valent iron nanoparticle-immobilized hybrid electrospun polymer nanofibrous mats, Colloids and Surfaces A: Physicochemical and Engineering Aspects 381 (2011) 48-54.

[15] H. Ma, Y. Huang, M. Shen, R. Guo, X. Cao, X. Shi, Enhanced dechlorination of trichloroethylene using electrospun polymer nanofibrous mats immobilized with iron/palladium bimetallic nanoparticles, J Hazard Mater 211-212 (2012) 349-356.

[16] C. Liu, X. Li, B. Ma, A. Qin, C. He, Removal of water contaminants by nanoscale zerovalent iron immobilized in PAN-based oxidized membrane, Applied Surface Science 321 (2014) 158-165. 
[17] H. Kim, H.-J. Hong, J. Jung, S.-H. Kim, J.-W. Yang, Degradation of trichloroethylene (TCE) by nanoscale zero-valent iron (nZVI) immobilized in alginate bead, Journal of hazardous materials 176 (2010) 1038-1043.

[18] J. Ren, Y.C. Woo, M. Yao, L.D. Tijing, H.K. Shon, Enhancement of nanoscale zerovalent iron immobilization onto electrospun polymeric nanofiber mats for groundwater remediation, Process Safety and Environmental Protection, (2017).

[19] S. Xiao, M. Shen, R. Guo, Q. Huang, S. Wang, X. Shi, Fabrication of multiwalled carbon nanotube-reinforced electrospun polymer nanofibers containing zero-valent iron nanoparticles for environmental applications, Journal of Materials Chemistry 20 (2010) 5700. [20] X. Wang, C. Chen, H. Liu, J. Ma, Preparation and characterization of PAA/PVDF membrane-immobilized $\mathrm{Pd} / \mathrm{Fe}$ nanoparticles for dechlorination of trichloroacetic acid, Water research 42 (2008) 4656-4664.

[21] L.S. Zhong, J.S. Hu, H.P. Liang, A.M. Cao, W.G. Song, L.J. Wan, Self-Assembled 3D flowerlike iron oxide nanostructures and their application in water treatment, Advanced Materials 18 (2006) 2426-2431.

[22] P.G. Tratnyek, R.L. Johnson, Nanotechnologies for environmental cleanup, Nano today $1(2006)$ 44-48.

[23] K. Arndt, A. Richter, S. Ludwig, J. Zimmermann, J. Kressler, D. Kuckling, H. Adler, Poly (vinyl alcohol)/poly (acrylic acid) hydrogels: FT-IR spectroscopic characterization of crosslinking reaction and work at transition point, Acta Polymerica 50 (1999) 383-390.

[24] J. Maurer, D. Eustace, C. Ratcliffe, Thermal characterization of poly (acrylic acid), Macromolecules 20 (1987) 196-202.

[25] J. Gilbert, J. Kipling, B. McEnaney, J. Sherwood, Carbonization of polymers IThermogravimetric analysis, Polymer 3 (1962) 1-10. 
[26] C.M. Cirtiu, T. Raychoudhury, S. Ghoshal, A. Moores, Systematic comparison of the size, surface characteristics and colloidal stability of zero valent iron nanoparticles pre-and post-grafted with common polymers, Colloids and Surfaces A: Physicochemical and Engineering Aspects 390 (2011) 95-104.

[27] H. Fu, X. Quan, Complexes of fulvic acid on the surface of hematite, goethite, and akaganeite: FTIR observation, Chemosphere 63 (2006) 403-410.

[28] Y.C. Woo, L.D. Tijing, W.-G. Shim, J.-S. Choi, S.-H. Kim, T. He, E. Drioli, H.K. Shon, Water desalination using graphene-enhanced electrospun nanofiber membrane via air gap membrane distillation, Journal of Membrane Science, 520 (2016) 99-110. 